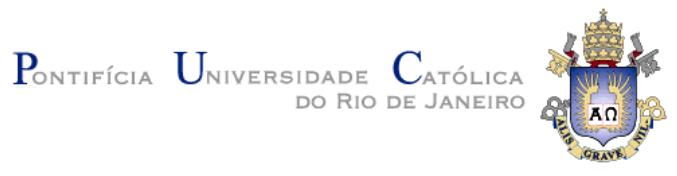

Flávia Miller Naethe Motta

De Crianças a Alunos: Transformações Sociais na Passagem da Educação Infantil para o Ensino Fundamental

Tese de doutorado

Tese apresentada ao Programa de PósGraduação em Educação do Departamento de Educação da PUC-Rio como parte dos requisitos parciais para obtenção do título de Doutor em Educação.

Orientadora: Profa. Sonia Kramer

Rio de Janeiro Março de 2010. 


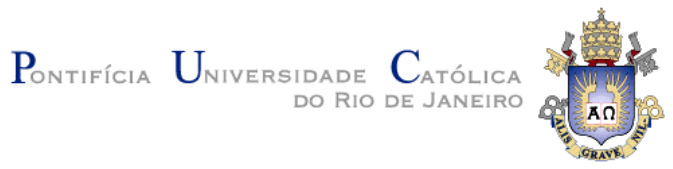

FLÁVIA MILLER NAETHE MOTTA

\section{De Crianças a Alunos: Transformações Sociais na Passagem da Educação Infantil para o Ensino Fundamental}

Tese apresentada como requisito parcial para obtenção do título de Doutor pelo Programa de Pós-Graduação em Educação do Departamento de Educação do Centro de Teologia e Ciências Humanas da PUC-Rio. Aprovada pela Comissão Examinadora abaixo assinada.

Prof $^{\text {a }}$. Sonia Kramer

Orientadora

Departamento de Educação - PUC - Rio Prof ${ }^{\text {a }}$ Isabel Alice Oswald Monteiro Lelis

Departamento de Educação - PUC - Rio

Maria Fernanda Rezende Nunes

Departamento de Educação - PUC - Rio

Prof ${ }^{\mathrm{a}}$ Maria Teresa de Assunção Freitas

Faculdade de Educação - UFJF

Prof ${ }^{a}$. Eloisa Acires Candal Rocha

Centro das Ciências da Educação - UFSC

Prof. Paulo Carneiro de Andrade

Coordenado setorial do Centro de Teologia e Ciências Humanas

PUC-Rio

Rio de Janeiro, 19 de março de 2010. 
Todos os direitos reservados. É proibida a reprodução total ou parcial do trabalho sem autorização da universidade, da autora e do orientador.

\section{Flávia Miller Naethe Motta}

Graduada em Psicologia pela Universidade Gama Filho (1991), Mestre em Educação pela Pontifícia Universidade Católica do Rio de Janeiro (2007) e Doutora em Educação pela Pontifícia Universidade Católica do Rio de Janeiro. Professora colaboradora do Curso de Especialização em Educação Infantil da Pontifícia Universidade Católica do Rio de Janeiro e Professora Assistente da Universidade Federal Rural do Rio de Janeiro. Tem experiência na área de Educação, com ênfase na Educação Infantil.

Ficha Catalográfica

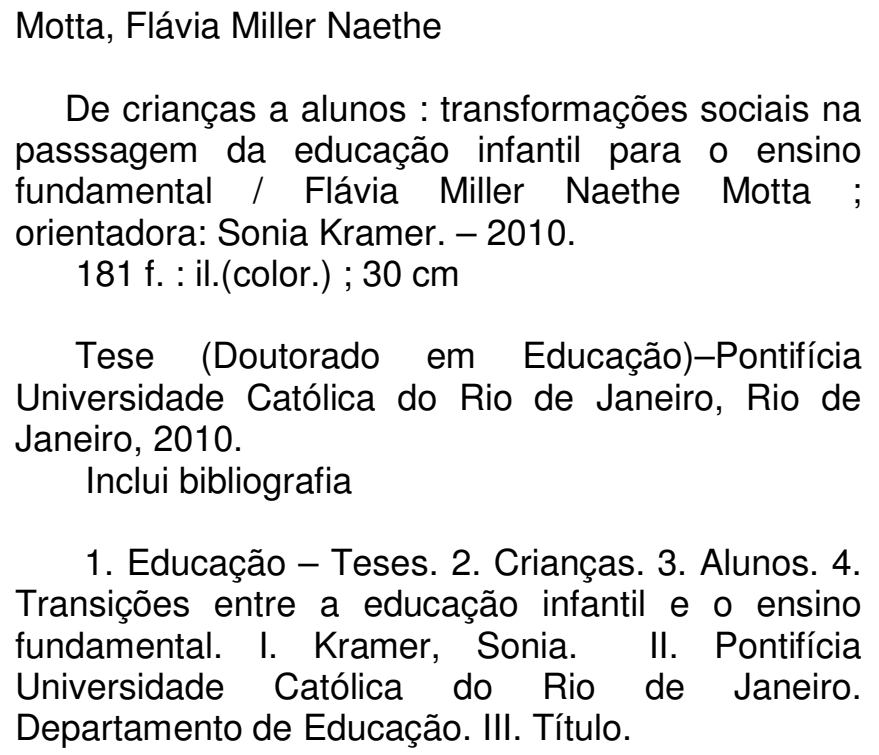

1. Educação - Teses. 2. Crianças. 3. Alunos. 4. Transições entre a educação infantil e o ensino fundamental. I. Kramer, Sonia. II. Pontifícia Universidade Católica do Rio de Janeiro. Departamento de Educação. III. Título. 


\section{AGRADECIMENTOS}

- À Sonia Kramer, que acreditou num projeto de vida acadêmico quando ele ainda mal se configurava como tal e que sempre soube "endurecer sem perder a ternura;

- Aos membros da banca examinadora que possibilitaram a composição da banca dos meus sonhos;

- A Maria Teresa Freitas que me ensinou a me apaixonar por Vigotski mostrando na prática o que o autor quis dizer com mediação;

- A Eloisa Candau Rocha pelas sugestões valiosas no exame de qualificação e pela sua forma calorosa de ser;

- A Isabel Alice Oswald Monteiro Lelis por suas sugestões sempre pertinentes no que tange à cultura escolar;

- Aos professores do Departamento de Educação da PUC-Rio que tanto contribuíram para estas reflexões;

- Ás participantes do Grupo de Pesquisa Crianças e Adultos em Diferentes Contextos: a Infância, a Cultura Contemporânea e a Educação, apoiado pelo CNPq e coordenado pela Prof ${ }^{a}$. Sonia Kramer, que compartilharam a construção de uma nova identidade profissional/acadêmica;

- Ao Dr. Alexandre Paranhos Silva Velloso Neto, terapeuta, ombro amigo, elemento fundamental em toda a reformulação vivenciada;

- A prefeitura do Município de Três Rios que tão bem acolheu essa pesquisa;

- A Direção da Escola Municipal pela colaboração e transparência durante o processo de pesquisa;

- Às professoras Márcia Cristina da Silva Carvalho, Cristiane Arbex Lourenço e Sirlane Medina da Silva Mata que generosamente abriram suas salas de aula à pesquisadora; 
- À Maria Lúcia Mello e Souza Peixoto, pela paciência em fazer traduções para o inglês;

- Ao Oscar Peixoto, melhor tio por afinidade que eu poderia ter encontrado;

- Ao Jorge, meu companheiro cúmplice e solidário, que embarcou nesse projeto de vida por inteiro, me apoiando sem reservas e amorosamente;

- Á Paula, Pedro e Carolina, meus filhos queridos que me deram a experiência da maternidade;

- Aos meus pais, Pedro e Sarita, em memória, pelo desafio de me superar sempre. 


\section{Resumo}

Motta, Flávia Miller Naethe; Kramer, Sonia. De Crianças a Alunos: Transformações Sociais na Passagem da Educação Infantil para o Ensino Fundamental. Rio de Janeiro, 2010. 181 p. Tese de Doutorado - Departamento de Educação, Pontifícia Universidade Católica do Rio de Janeiro.

A temática desta tese trata da passagem das crianças da Educação Infantil para o Ensino Fundamental e da ação da cultura escolar sobre as culturas infantis, transformando os agentes sociais crianças em agentes sociais alunos. A pesquisa foi numa unidade da rede municipal do Município de Três Rios, Rio de Janeiro. Os fundamentos teórico-metodológicos foram tecidos através de diálogos com os conceitos elaborados especialmente por Bakhtin, Vigotski, Foucault, Certeau e Sacristán. Cada um desses autores contribuiu de maneira específica para a análise das questões levantadas. Os conceitos operaram em três planos: de um lado tivemos a concepção de linguagem de Bakhtin, principal categoria de análise dos dados do campo e Vigotski fornecendo subsídios para um pensamento dialético em torno das culturas infantil e escolar tomadas como textos. Em outro plano, consideramos Foucault e Certeau na análise das estratégias de poder e das táticas de resistência encontradas nas práticas observadas e suas influências na subjetivação dos sujeitos. Por fim, a sociologia da infância e o conceito de cultura escolar permitiram explicitar elementos do campo colocando-os num contexto. Para abordar as transições e as rupturas percebidas nesse processo, as contribuições principais foram definidas a partir de Moss e Corsaro e Molinari.

\section{Palavras-chave:}

Crianças, alunos, transições entre a educação infantil e o ensino fundamental 


\begin{abstract}
Motta, Flávia Miller Naethe; Kramer, Sonia From a Little Child to A Student: Social Transformation in the Transition from Early Childhood Education for Elementary School. Rio de Janeiro, 2010. 181 p. Tese de Doutorado Departamento de Educação, Pontifícia Universidade Católica do Rio de Janeiro.
\end{abstract}

The theme of this thesis deals with the transition of children from early Childhood Education to Elementary School and with the action of school culture over children's cultures, transforming children as social agents into students as social agents. The research was carried out in a unit of the government (municipal) schools in the city of Três Rios, Rio de Janeiro. The theoreticmethodological fundaments have been created through dialogues with the concepts elaborated especially by Bakhtin, Vigotski, Foucault, Certeau and Sacristán. Each one of these authors contributed in a specific way for the analysis of the questions raised here. The concepts have operated on three plans: on one side we had the conception of language of Bakhtin, which is the main category of analysis of the field data, and Vigotski supplying subsidies for a dialectical thinking about school culture and children's cultures taken as texts. On another level, we considered Foucault and Certeau's analysis of power strategies and tactics of resistance found in the practices observed and their influence on the subjectivation of the subjects. Finally, the sociology of childhood and the concept of school culture allowed clarifying elements of the field by placing them in context. To address the transition and the disruptions perceived in this process, the major contributions were set from Moss, Corsaro and Molinari.

\title{
Key-Words:
}

Children, students, transitions from early Childhood Education for Elementary School 
SUMÁRIO

1. Notas Iniciais 11

2. A Escola Municipal Joaquim Silva: Começando pelo Campo 22

$\begin{array}{ll}2.1 \text { Chegando a Três Rios } & 23\end{array}$

2.2 Dados Gerais Relativos à Educação Infantil no Município 25

2.3 Entrando na Escola

2.4 A Educação Infantil no $3^{\circ}$ Período 34

2.4.1 Uma prática pedagógica sedutora 35

2.4.2 As interações com a pesquisadora 38

2.4.3 Questões de poder e de gênero no $3^{\circ}$ período 41

2.5 O Primeiro Dia de Aula no $1^{\circ}$ Ano do Ensino Fundamental 52

2.6 Mudando os Rumos da Pesquisa: Preservando o Essencial 62

3. Colocando as Tensões em Confronto: o Método Dialético como

Ponto de Partida para a Construção do Campo Teórico 64

3.1 Recorrendo à Dialética: Apropriações

3.2 Vigotski e o Método Dialético: Contribuições da Psicologia $\begin{array}{lc}\text { Sóciocultural } & 68\end{array}$

3.2.1 A dialética em Vigotski

$\begin{array}{ll}\text { 3.2.2 A subjetividade segundo a psicologia sociocultural } & \mathbf{7 4}\end{array}$

3.3 Bakhtin: Interações e Diálogos na Construção Discursiva 79

3.3.1. A dialogicidade e a construção da pesquisa $\quad 80$

$\begin{array}{ll}\text { 3.3.2 O sujeito bakhtiniano e a alteridade } & 84\end{array}$

3.4 Entrelaçando os Discursos: um Diálogo em Torno da Idéia de Subjetividade $\quad 86$

3.5 A Forma Escolar: o Processo e Sua Gênese 90

4. Entrecruzando Planos de Análise: Em Busca das Tensões que $\begin{array}{ll}\text { Desvelam a Empiria } & 97\end{array}$

4.1 Foucault e Certeau: uma Analítica da Disciplina e da Resistência 98

$\begin{array}{ll}\text { 4.2 Culturas Infantis e Cultura Escolar } & 104\end{array}$

$\begin{array}{ll}\text { 4.2.1 Infância e cultura: as culturas infantis como recriação do } & 104\end{array}$ 
mundo

4.2.2 A cultura escolar como um texto

4.2.3 Sacristán: o currículo como dispositivo de poder e a invenção do

113 aluno

5. Entretecendo os Textos a Partir do Contexto 119

5.1 A Ação das Crianças: Expressão das Culturas de Pares 120

5.2 Os Corpos como Elementos da Fabricação de Alunos 124

5.3 A Disciplina em Exercício: Exames e Sanções 129

5.4 Desvelando Alguns Aspectos de Estar Escolarizado 133

5.5 Crianças e Alunos: O Cotidiano e as Táticas de Resistência 142

5.6 Sobre Transições e Rupturas

$\begin{array}{ll}\text { 6. Considerações Finais } & 157\end{array}$

$\begin{array}{ll}\text { Referências Bibliográficas } & 165\end{array}$ 


\section{QUADROS, GRÁFICOS E TABELAS}

Tabela 1 - Distribuição de matrículas no pré-escolar 25

$\begin{array}{ll}\text { Tabela } 2 \text { - Cobertura de atendimento } & 27\end{array}$

Tabela 3 - Distribuição das crianças por cor e sexo declarados pelo 31 responsável

Tabela 4 - Profissões dos pais 31

Tabela 5 - Profissões das mães

Tabela 6 - Faixa de renda familiar mensal $\quad 32$

Tabela 7 - Religião familiar declarada 33

Gráfico 1 - Matrículas totais no município de Três Rios 26

Gráfico 2 - Estabelecimentos de ensino no município de Três Rios 26

Gráfico 3 - Número de docentes no município de Três Rios 27

$\begin{array}{ll}\text { Gravura 1- Lucas escreve seu nome } & 40\end{array}$

Gravura 2 - Mapa da sala de aula do $3^{\circ}$ período $\quad 45$

Foto1 - A sala organizada em fileiras, professora à frente 130

$\begin{array}{ll}\text { Foto } 2 \text { - As transparências da escola } & 130\end{array}$

$\begin{array}{ll}\text { Foto 3- Mariana corrige Kauã (começo) } & 138\end{array}$

$\begin{array}{ll}\text { Foto } 4 \text { - Mariana corrige Kauã (meio) } & 139\end{array}$

$\begin{array}{ll}\text { Foto } 5 \text { - Mariana corrige Kauã (fim) } & 139\end{array}$

$\begin{array}{ll}\text { Foto } 6 \text { - Kauã conversa com Caio } & 146\end{array}$

Foto 7 - Renan, de pé ao lado de Lucas 146

$\begin{array}{ll}\text { Foto } 8 \text { - Caio faz a tarefa de pé } & 146\end{array}$

Foto 9- Júlio César começa a pescaria da borracha e apontador 147

$\begin{array}{ll}\text { Foto } 10 \text { - Júlio César continua a pescaria } & 148\end{array}$

Foto 11 - Kauã e o avião (começo) 148

$\begin{array}{ll}\text { Foto } 12 \text { - Kauã e o avião (meio) } & 149\end{array}$

$\begin{array}{ll}\text { Foto } 13 \text { - Kauã e o avião (final) } & 149\end{array}$

$\begin{array}{ll}\text { Foto } 14 \text { - Paulo passa a borracha para o irmão } & 150\end{array}$

$\begin{array}{ll}\text { Foto } 15 \text { - Paulo ajuda Kauã } & 150\end{array}$

Foto 16 - Kauã busca auxílio com Paulo 151

$\begin{array}{ll}\text { Anexos } & 172\end{array}$ 